07,01

\title{
Влияние температуры деформации осадкой на формирование мелкозернистой структуры литого сплава системы $\mathrm{Ni}-\mathrm{Mn}-\mathrm{Ga}$
}

\author{
() И.И. Мусабиров ${ }^{1}$, И.М. Сафраров ${ }^{1}$, И.3. Шарипов ${ }^{2}$, М.И. Нагимов ${ }^{1}$, В.В. Коледов ${ }^{3}$, \\ В.В. Ховайло ${ }^{4}$, Р.P. Мулюков 1 \\ ${ }^{1}$ Институт проблем сверхпластичности металлов РАН, \\ Уфра, Россия \\ ${ }^{2}$ Уфимский государственный авиационный технический университет, \\ Уфа, Россия \\ ${ }^{3}$ Институт радиотехники и электроники РАН, \\ Москва, Россия \\ ${ }^{4}$ Национальный исследовательский технологический университет „МИСиС“, \\ Москва, Россия \\ E-mail: irekmusabirov@mail.ru
}

(Поступила в Редакцию 13 декабря 2016 г.)

Исследованы пластическое поведение в процессе деформации осадкой и ее влияние на микроструктуру в поликристаллическом сплаве $\mathrm{Ni}_{2.19} \mathrm{Fe}_{0.04} \mathrm{Mn}_{0.77} \mathrm{Ga}$. Методом анализа температурной зависимости удельной намагниченности установлены температуры мартенситного и магнитного фазовых превращений, которые имеют следующие значения: $M_{F}=320 \mathrm{~K}, A_{S}=360 \mathrm{~K}, T_{C}=380 \mathrm{~K}$. С помощью дифференциальносканирующей калориметрии показано, что при нагреве образца в интервале температур 930-1070 K в сплаве наблюдается фазовый переход из упорядоченной фазы $L 2_{1}$ в разупорядоченную фазу $B 2$. Температура плавления составляет $1426 \mathrm{~K}$. Анализ диаграмм нагружения, построенных при осаждении образца при температурах 773, 873 и $973 \mathrm{~K}$, показывает, что при температуре $773 \mathrm{~K}$ поведение кривой напряжение-деформация свойственно холодной деформации. Характер кривых зависимости для температур 873 и 973 К типичен для горячей деформации. После деформации сплава исследована его микроструктура с помощью сканирующей электронной микроскопии в режиме обратно отраженных электронов. Пластическая деформация сплава при исследуемых температурах приводит к фрагментации зеренной структуры в области локализованной деформации. При всех температурах наблюдается рекристаллизованная зеренная структура. Установлено, что после осадки при $973 \mathrm{~K}$ наблюдается неравномерная рекристаллизация структуры вследствие интенсивности этого процесса при столь высокой температуре. Наиболее однородной по среднему размеру зерен является микроструктура сплава после пластической деформации при температуре $873 \mathrm{~K}$.

Деформационно-термическая обработка сплава, дифференциально-сканирующая калориметрия и исследование микроструктуры материала выполнены при финансовой поддержке РФФИ в рамках научного проекта № 16-32-60159 мол_а_дк. Выплавка сплава и анализ фазовых превращений в области комнатных температур выполнены при поддержке РНФ, грант №14-22-00279.

DOI: 10.21883/FTT.2017.08.44756.441

\section{1. Введение}

Сплавы Гейслера системы $\mathrm{Ni}-\mathrm{Mn}-\mathrm{Ga}$ относятся к классу функциональных материалов. В этих материалах в области протекания мартенситного превращения наблюдаются ферромагнитный эффект памяти формы [1-6], гигантский магнитокалорический эффект [7-10] и др. Данное фазовое превращение в материалах протекает вблизи комнатных температур. Функциональные характеристики сплавов позволяют рассматривать их в качестве потенциальных кандидатов для применения в различного рода управляемых устройствах, микроактюаторах, магнитных холодильниках на основе твердотельного хладагента. Максимальные функциональные эффекты наблюдаются на монокристаллических образцах сплавов. Так, на монокристалле сплава $\mathrm{Ni}_{2} \mathrm{MnGa}$ получена необратимая магнитоиндуцированная деформация около 9.5\% в поле $1 \mathrm{~T}$ [11]. На поликристаллических образцах этот эффект имеет на порядок меньшую величину [12]. Однако даже этого достаточно для применения на практике. Существенным недостатком данных сплавов является их подверженность разрушению при циклировании через температуру мартенситного превращения. Как известно, применение к различным металлам и сплавам термомеханической обработки приводит к повышению механических характеристик [13-15]. Для исследуемых поликристаллических сплавов Гейслера обработка деформационными методами является одним из решений задачи повышения стабильности функциональных эффектов в материалах. Кручение под гидростатическим давлением при комнатной температуре позволяет получить в сплавах нанокристаллическую структуру на образцах в форме дисков толщиной до $1 \mathrm{~mm}$ и диаметром от 10 до $20 \mathrm{~mm}$. Однако в таком структурном состоянии в материале не наблюдается мартенситного превращения и вследствие 
размерного фактора отсутствует ферромагнитное упорядочение [16-19]. Другой метод деформационной обработки различных металлов и сплавов - прокатка при различных температурах - позволяет получить протяженные ленты материала с ультрамелкозернистой структурой [20]. Плюсом данного метода обработки наряду с модифицированием зеренной микроструктуры является получение достаточно острой кристаллографической текстуры в совокупности с внутренними напряжениями в материале $[21,22]$. В литературе также встречаются публикации по обработке сплавов Гейслера методом экструзии [23]. Обработка этим методом, как и в случае прокатки, позволяет получить острую кристаллографическую текстуру в заготовке в форме прутка толщиной в несколько миллиметров. Формирование деформационными методами в обрабатываемом материале как кристаллографической текстуры, так и внутренних напряжений также является одной из важных задач повышения функциональных характеристик материала $[24,25]$.

Вследствие низкой пластичности исследуемых сплавов деформационную обработку необходимо проводить в области выше комнатных температур. Для этого нужно провести изотермические исследования механических свойств сплавов при различных температурах. Соответствующие результаты позволят распространить их на другие методы деформационной обработки сплавов Гейслера. В частности, эти данные необходимы для планируемой пластической деформации исследуемых сплавов методом всесторонней изотермической ковки (ВИК). Известно, что с помощью этого метода возможно получение модифицированной зеренной структуры, кристаллографической текстуры и внутренних напряжений в различных металлах и сплавах [26-28]. Отличием данного метода обработки от описанных выше состоит в том, что обрабатываемый образец имеет сравнительно большие размеры. Однако для реализации пластической деформации материала методом ВИК необходимы данные о температурном интервале пластичности обрабатываемого сплава. В настоящей работе представлены результаты исследования пластического поведения и микроструктуры поликристаллического сплава $\mathrm{Ni}_{2.19} \mathrm{Fe}_{0.04} \mathrm{Mn}_{0.77} \mathrm{Ga}$, деформированного методом осаждения в области температур фазового превращения $L 2_{1} \leftrightarrow B 2$.

\section{2. Материалы и методика эксперимента}

В качестве материала исследований был выбран поликристаллический сплав $\mathrm{Ni}_{2.19} \mathrm{Fe}_{0.04} \mathrm{Mn}_{0.77} \mathrm{Ga}$, который был изготовлен методом аргонно-дуговой плавки из элементов $\mathrm{Ni}, \mathrm{Fe}, \mathrm{Mn}$ и $\mathrm{Ga}$ высокой чистоты. Для гомогенизации полученные образцы отжигались в течение 9 дней при $1100 \mathrm{~K}$ с последующей закалкой в воду с тающим льдом.

Анализ температур мартенситного и магнитного фазовых превращений проведен методом записи температур-

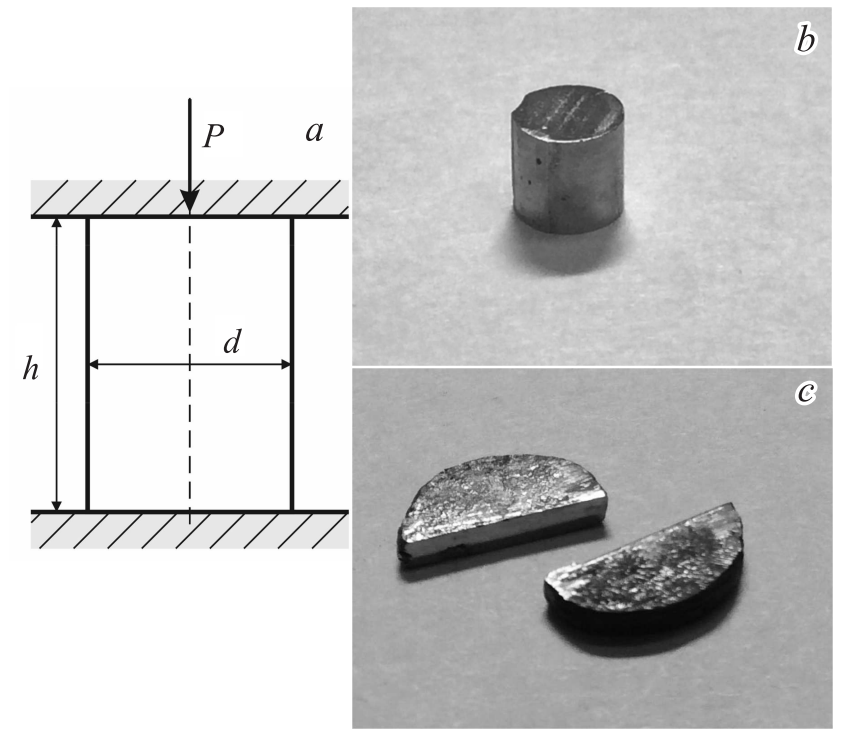

Рис. 1. Схема пластической деформации образца сплава $\mathrm{Ni}_{2.19} \mathrm{Fe}_{0.04} \mathrm{Mn}_{0.77} \mathrm{Ga}$ методом осадки $(a)$ и макроскопическое изображение образца до деформации $(b)$ и после осадки $(c)$.

ной зависимости удельной намагниченности на автоматических магнитных микровесах в магнитных полях 80 и $240 \mathrm{kA} / \mathrm{m}$. Измерения проведены при нагреве и охлаждении образца в интервале температур от 220 до $410 \mathrm{~K}$. Ввиду принципиальной схемы установки абсолютную величину намагниченности исследуемого образца можно определить только при сравнении данных измерений с данными для эталонного материала, имеющего такие же форму и размеры. В работе представлены результаты в относительных единицах (удельная намагниченность), поскольку в данном случае интересны только температуры фазовых превращений и относительное изменение намагниченности образца при его переходе из одной фазы в другую. За единицу принято значение намагниченности образца в магнитном поле $240 \mathrm{kA} / \mathrm{m}$ при температуре $223 \mathrm{~K}$. Исследование температур фазовых превращений в области высоких температур вплоть до температуры плавления проведено методом дифференциальной сканирующей калориметрии (ДСК) на установке NETZSCH STA 449 F1 Jupiter. Возможности прибора позволяют проводить анализ фазовых переходов в интервале температур от 373 до $1773 \mathrm{~K}$ в инертной газовой среде (Ar). Образец в форме „таблетки“ с диаметром $4 \mathrm{~mm}$ и высотой $2 \mathrm{~mm}$ после полировки контактной поверхности на алмазной пасте для наилучшего теплового контакта помещается в корундовый тигель. Перед измерением осуществлялась трехкратная продувка газом измеряемой системы.

Пластическая деформация методом осадки и запись диаграмм нагружения осуществлялись на машине сложного нагружения Schenck Trebel RMC 100. Схема осадки представлена на рис. 1, $a$. Для исследований из слитка сплава были вырезаны образцы в форме цилиндра с 
диаметром $d$ и высотой $h$, равными $5 \mathrm{~mm}$ (рис. $1, b$ ). Нагружение образца вдоль оси цилиндра производилось после достижения им необходимой температуры и выдерживания в течение $\sim 15 \mathrm{~min}$. Осадка на величину около $60-70 \%$ проводилась со скоростью $\dot{\varepsilon} \approx 10^{-4}$.

Исследование микроструктуры образцов после деформационной обработки проводилось с помощью растрового электронного микроскопа высокого разрешения Tescan Mira 3 LMH в режиме регистрации обратно отраженных электронов. Такой метод позволяет анализировать зеренную микроструктуру материала на сравнительно большой площади с разрешением зерен вплоть до сотни нанометров. После осадки цилиндрической заготовки были получены образцы в форме таблеток. Затем они были разрезаны электроискровым методом в плоскости, параллельной оси осадки и соответственно оси исходной цилиндрической заготовки. Макрофотография полученных образцов представлена на рис. 1,c. Плоскость среза подвергалась шлифованию на абразивной бумаге и электрополировке в растворе электролита с составом $90 \%$ бутанол $+10 \% \mathrm{HCl}$. Основное внимание при анализе микроструктуры уделялось центральной части шлифа, соответствующей области локализованной деформации. Следует отметить, что исследование микроструктуры материала проводилось при комнатной температуре.

\section{3. Экспериментальные результаты}

3.1. Термомагнитный анализ литого сплава в области существования мартенситного и магнитного фазовых превращений. Анализ температур фазовых превращений в области комнатных температур проведен методом записи кривой температурной зависимости намагниченности. Соответствующие результаты представлены на рис. 2. Из рисунка видно, что удельная намагниченность образца

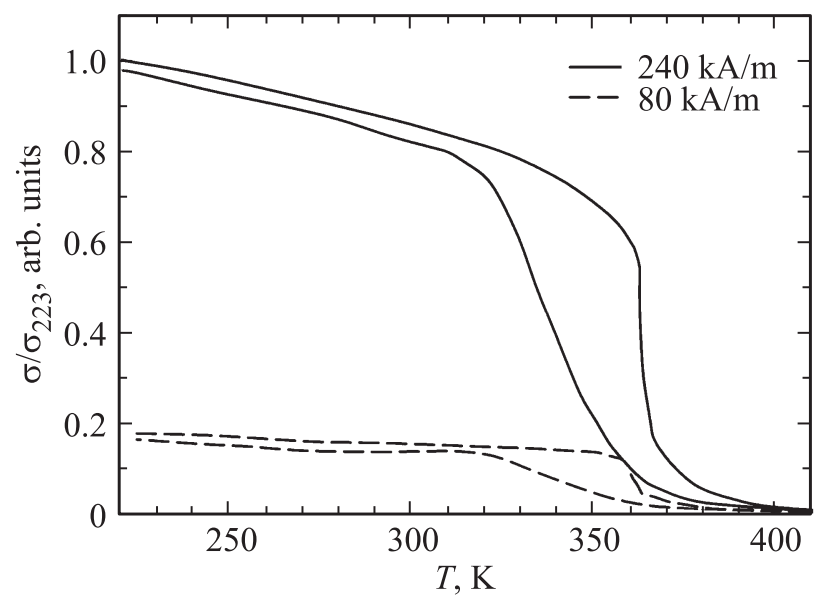

Рис. 2. Температурная зависимость удельной намагниченности поликристаллического сплава $\mathrm{Ni}_{2.19} \mathrm{Fe}_{0.04} \mathrm{Mn}_{0.77} \mathrm{Ga}$ в исходном литом состоянии в магнитных полях 80 и $240 \mathrm{kA} / \mathrm{m}$. при температуре $223 \mathrm{~K}$ в магнитном поле $80 \mathrm{kA} / \mathrm{m}$ составляет $19 \%$ от ее значения в поле $240 \mathrm{kA} / \mathrm{m}$. Нагрев образца от температуры $223 \mathrm{~K}$ в магнитном поле $80 \mathrm{kA} / \mathrm{m}$ приводит к постепенному снижению величины удельной намагниченности. При температуре $360 \mathrm{~K}$ на кривой наблюдаются перегиб и снижение намагниченности образца практически до нуля при температуре $380 \mathrm{~K}$. Такое поведение кривой соответствует переходу сплава из ферромагнитного состояния в парамагнитное с точкой Кюри $380 \mathrm{~K}$. На самом деле эта точка является приблизительно точкой Кюри, поскольку точное ее определение необходимо проводить немагнитными методами. При охлаждении образца от температуры $410 \mathrm{~K}$ его удельная намагниченность с некоторым гистерезисом начинает возрастать. Однако в отличие от поведения намагниченности при нагреве в этом случае скачкообразного возрастания намагниченности не наблюдается. Происходит монотонное возрастание намагниченности. При $320 \mathrm{~K}$ она достигает значения, которое имела в цикле нагрева образца. Дальнейший ход кривой охлаждения практически совпадает с кривой нагрева. Такой вид кривой (гистерезиса) свидетельствует о том, что температуры мартенситного и магнитного фазовых превращений накладываются друг на друга. В этом случае говорят о связанном магнитоструктурном фазовом превращении. При определенном сочетании элементов сплава такой переход наблюдается для других составов [29,30]. При увеличении напряженности приложенного магнитного поля до $240 \mathrm{kA} / \mathrm{m}$ характер кривой $\sigma(T)$ практически не изменяется. Однако в этом случае наблюдается некоторое смещение кривой нагрева в область более высоких температур. Как известно, это обусловлено влиянием магнитного поля как на температуру мартенситного превращения, так и на температуру магнитного превращения [31]. Кривая охлаждения при этом не показывает смещения по температуре.

3.2. Дифференциальная сканирующая калориметрия. На рис. 3 представлены результаты анализа температур фазовых превращений в сплаве при температурах выше комнатной вплоть до температуры плавления методами ДСК. Запись данных проводилась при нагреве образца в интервале температур 430-1500 К. Из рисунка видно, что на кривой наблюдаются две области с наличием эндотермических пиков, кардинально различающихся величиной поглощаемой энергии превращения. Детальный анализ первого пика в области 770-1270 K представлен на вставке.

Рассмотрение этой области температур показывает, что на кривой ДСК при температуре $930 \mathrm{~K}$ наблюдается перегиб, соответствующий началу фазового превращения. Это превращение протекает в сплаве вплоть до температуры $1070 \mathrm{~K}$. Согласно литературным данным, в сплавах исследуемой системы в этой области температур наблюдается фазовое превращение (при нагреве образца) упорядоченной фазы $L 2_{1}$ в разупорядоченную фазу B2 [32-34]. Второй эндотермический пик на кривой ДСК при температуре $1426 \mathrm{~K}$ показывает достаточно 


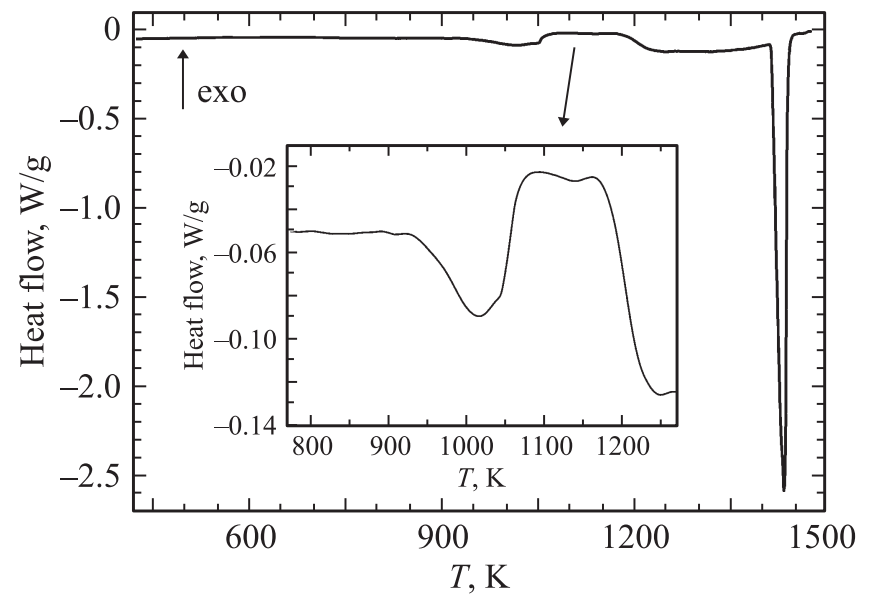

Рис. 3. Результаты дифференциальной сканирующей калориметрии при нагреве образца поликристаллического сплава $\mathrm{Ni}_{2.19} \mathrm{Fe}_{0.04} \mathrm{Mn}_{0.77} \mathrm{Ga}$ в исходном литом состоянии.

большое поглощение теплоты. Пик такой энергии соответствует фазовому превращению - переходу сплава в расплавленное состояние.

3.3. Диаграммы деформации сплава. Выбор температур пластического деформирования сплава обусловлен несколькими моментами. Так, согласно литературным данным, сплавы Гейслера способны пластически деформироваться при температурах фазового превращения $L 2_{1} \leftrightarrow B 2$, которое в случае исследуемого сплава протекает в интервале $930-1070 \mathrm{~K}$ и выше. Но при высоких температурах обработки ускоряются адгезионные процессы, которые способны привести к загрязнению структуры окислами и, как следствие, к снижению функциональных характеристик материала. Следовательно, необходимо было найти некий оптимум температур, позволяющий провести пластическую деформацию материала и не допустить окисления заготовки. Как показано в работе [35], окислительные про-

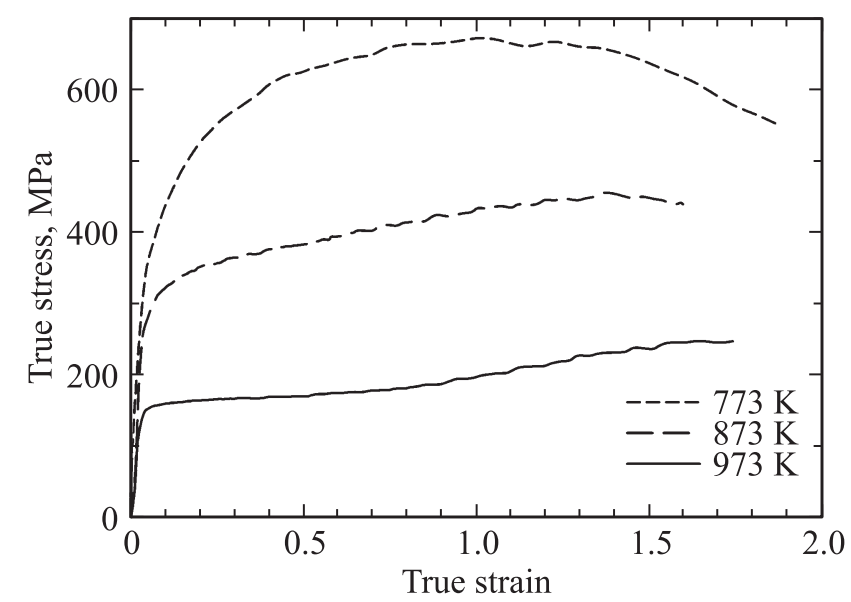

Рис. 4. Зависимости напряжение-деформация поликристаллического сплава $\mathrm{Ni}_{2.19} \mathrm{Fe}_{0.04} \mathrm{Mn}_{0.77} \mathrm{Ga}$ при температурах 773 , 873 и $973 \mathrm{~K}$. цессы активизируются при температурах около $873 \mathrm{~K}$ и незначительно изменяют физические свойства образца даже при температурах $973 \mathrm{~K}$. Исходя из этого для исследуемого сплава были выбраны три температуры пластической деформации осадкой. Температуры 773 и $873 \mathrm{~K}$ лежат ниже температуры фазового превращения $L 2_{1} \leftrightarrow B 2$, а температура $973 \mathrm{~K}$ лежит в интервале температур этого фазового превращения. Выбор температур был осуществлен аналогично исследованию температурного интервала пластичности для сплава системы $\mathrm{Ni}-\mathrm{Mn}-\mathrm{In}[36]$.

В процессе осаждения цилиндрических образцов проводилась запись диаграмм нагружения. На рис. 4 представлены кривые напряжение-деформация $(s-e)$ при температурах 773, 873 и $973 \mathrm{~K}$. Из рисунка видно, что повышение температуры деформации приводит к значительному снижению напряжений течения, а кривые деформации при этом становятся более монотонными.

При температуре $773 \mathrm{~K}$ кривая на первых стадиях деформации шла вверх, достигала максимума, после чего начинала снижаться, т.е. при этой температуре вначале шел процесс деформационного упрочнения, более свойственный холодной деформации, и только при достижении достаточной плотности дефектов начинался процесс разупрочнения в результате динамического возврата.

Характер кривых зависимости напряжение-деформация для температур 873 и $973 \mathrm{~K}$ типичен для горячей деформации, т. е. кривая уже при небольших деформациях переходит в стадию установившейся деформации. Постепенное монотонное повышение напряжения течения обусловлено постепенным увеличением поперечного сечения образца при осадке. На установившейся стадии деформации на кривых $s-e$ наблюдалась осцилляция напряжения течения, обусловленная циклической сменой процессов деформационного наклепа и релаксации структуры в результате динамического возврата.

3.4. Микроструктура сплава в различных структурных состояниях. С целью установления характера процессов динамического возврата, идущих в сплаве при указанных температурах деформации, были проведены электронно-микроскопические исследования полученных осадкой состояний. Для анализа микроструктуры сплава после пластической деформации осадкой был подготовлен образец из центральной, наиболее проработанной области образца без застойных зон, характерных для деформации осадкой. На рис. 5 представлены результаты съемки микроструктуры образцов после осадки сплава при температурах $773(a)$, $873(b)$ и $973 \mathrm{~K}(c)$. Видно, что осадка при $773 \mathrm{~K}$ приводит к фрагментации зеренной структуры. В результате процессов рекристаллизации формируются новые зерна размером от $200 \mathrm{~nm}$ до $1 \mu \mathrm{m}$. При увеличении температуры пластической деформации сплава до $873 \mathrm{~K}$ разброс в размерах зерен уменьшается, средний размер составляет порядка одного микрометра. 

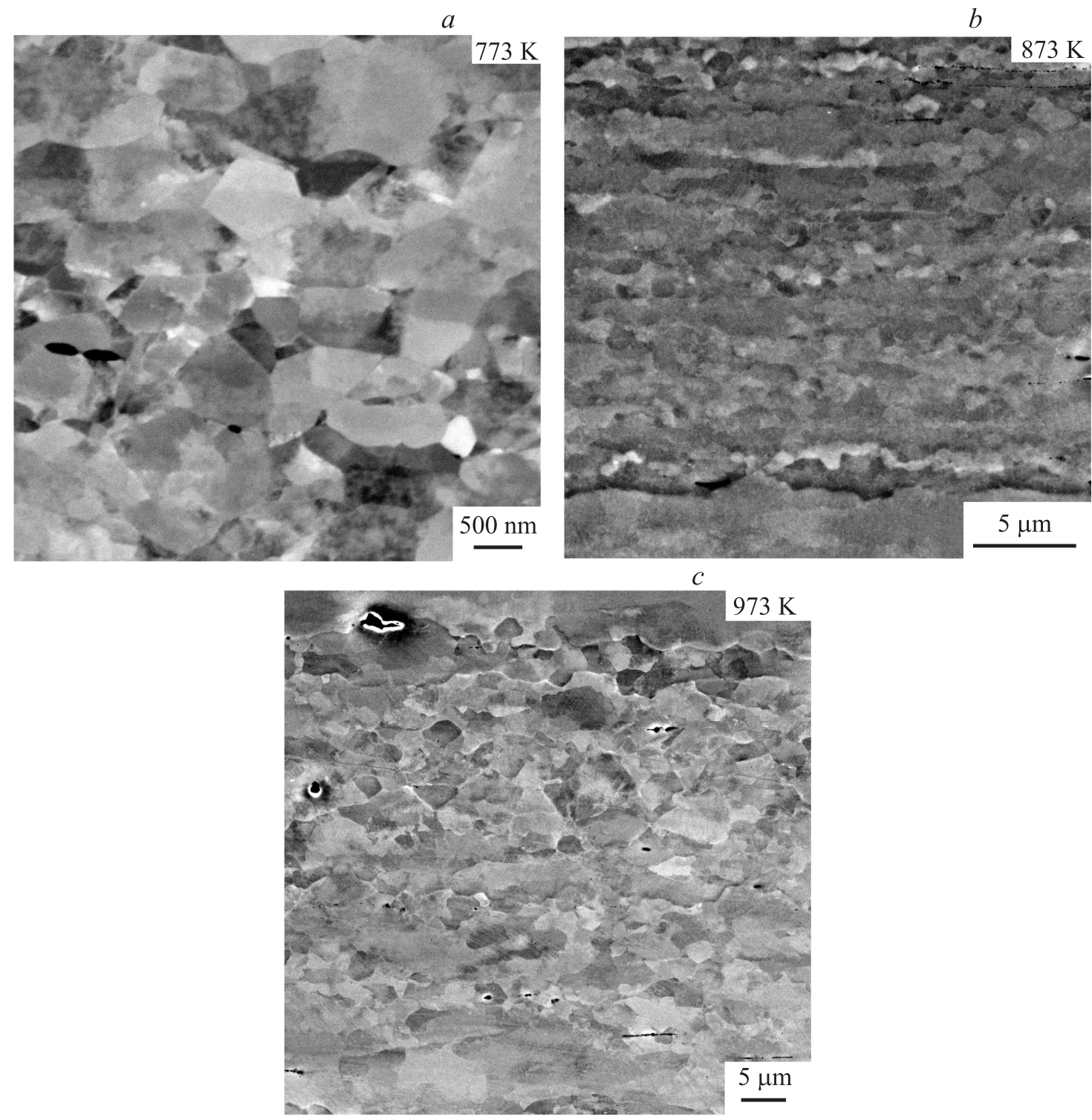

Рис. 5. Микроструктура в режиме обратно отраженных электронов поликристаллического сплава $\mathrm{Ni}_{2.19} \mathrm{Fe}_{0.04} \mathrm{Mn}_{0.77} \mathrm{Ga}_{\text {после }}$ осадки при температурах $773(a), 873(b)$ и $973 \mathrm{~K}(c)$.

Повышение температуры осадки до $973 \mathrm{~K}$ приводит к резкой активизации рекристаллизации, которая идет неоднородно, и часть зерен растет быстрее остальных, в результате наблюдается разброс в размерах зерен от 1 до $10 \mu \mathrm{m}$.

\section{4. Обсуждение результатов}

Исследования поликристаллических сплавов Гейслера показывают, что при совпадении температур мартенситного и магнитного фазовых превращений эффекты магнитоиндуцированной памяти формы имеют бо́льшие величины, чем для сплавов, в которых эти превращения протекают при разных температурах. В случае исследуемого состава эти превращения накладываются друг на друга. Таким образом, это удовлетворяет критерию получения как можно большего эффекта на сплавах Гейслера, подвергнутых деформационно-термической обработке различными методами. Однако на данном этапе исследований анализ функциональных эффектов сплава после обработки не входил в цели работы и не проводился. Основной задачей было проведение анализа пластичности материала при деформационной обработке при различных температурах.

Установившаяся стадия течения и осцилляции кривой деформирования сплава при температурах $773-973 \mathrm{~K}$ свидетельствует о протекании процессов динамической рекристаллизации. Однако при меньшем значении выбранного диапазона температур деформации энергия активации процессов возврата остается достаточно высокой из-за низкой диффузионной подвижности атомов, 
в результате чего необходимо было набрать довольно высокую критическую плотность дислокаций, прежде чем начали образовываться зародыши рекристаллизации и расти новые, свободные от дислокаций зерна, приводя к снижению напряжения течения. Соответственно структурная релаксация сплава, приводящая к снижению напряжения течения, при $773 \mathrm{~K}$ начинается на последних стадиях деформации.

При более высокой температуре деформации скорость диффузионных процессов резко возрастает, что приводит к более интенсивной эволюции дислокационной структуры и ускорению процессов динамического возврата, вследствие чего стадия установившейся деформации начинается при гораздо меньших степенях деформации и сопровождается осцилляциями напряжения, характерными для динамической рекристаллизации. При этом характер кривых деформирования при температурах 873 и $973 \mathrm{~K}$, несмотря на двукратную разницу в величине напряжения течения, практически одинаков, что свидетельсвует о тождественности процессов структурной эволюции при этих температурах. Следовательно, деформирование при указанных температурах будет практически равнозначным для получения мелкозернистой структуры. Но поскольку вторым критерием при выборе оптимальной температуры деформации является необходимость избежать окисления сплава при термическом воздействии, предпочтение следует отдать более низкой температуре деформации, т. е. температуре 873 К. Таким образом, наиболее эффективной для получения образцов сплава с однородной мелкозернистой структурой методом ВИК будет деформация при температуре $873 \mathrm{~K}$.

\section{5. Заключение}

В результате исследования влияния температуры деформации осадкой на формирование мелкозернистой структуры литого поликристаллического сплава $\mathrm{Ni}_{2.19} \mathrm{Fe}_{0.04} \mathrm{Mn}_{0.77} \mathrm{Ga}$, его микроструктуру и характер протекания процесса деформации можно сделать следующие выводы.

1. В поликристаллическом сплаве $\mathrm{Ni}_{2.19} \mathrm{Fe}_{0.04} \mathrm{Mn}_{0.77} \mathrm{Ga}$ в области комнатных температур наблюдаются мартенситное и магнитное фазовые превращения, совпадающие по температуре. Точки фазовых превращений имеют следующие значения: $M_{F}=320 \mathrm{~K}$ (окончание мартенситного превращения), $A_{S}=360 \mathrm{~K}$ (начало аустенитного превращения), $T_{C}=380 \mathrm{~K}$.

2. В области высоких температур в интервале 930-1070 K в сплаве наблюдается фазовое превращение упорядоченной фазы $L 2_{1}$ в разупорядоченную фазу $B 2$. Температура плавления сплава составляет $1426 \mathrm{~K}$.

3. При температуре $773 \mathrm{~K}$ процессы дислокационной перестройки сильно тормозятся вследствие низкой скорости диффузии атомов, что сильно затрудняет процессы динамической рекристаллизации. При температуpax 873 и $973 \mathrm{~K}$ более низкая энергия активации струк- турной релаксации приводит к началу процессов динамического возврата уже на начальных стадиях деформирования. Это позволяет предполагать, что деформирование при 873 и $973 \mathrm{~K}$ более эффективно с точки зрения формирования микрозернистой структуры. Следовательно, с учетом необходимости снижения температуры деформирования для уменьшения процессов окисления сплава наиболее оптимальным (приоритетным) будет выбор для деформации температуры $873 \mathrm{~K}$.

\section{Список литературы}

[1] Х.Я. Мулюков, И.И. Мусабиров. ЖТФ 78, 6, 129 (2008).

[2] V.D. Buchelnikov, V.V. Khovailo, T. Takagi. J. Magn. Magn. Mater. 300, 1, e459 (2006).

[3] W.H. Wang, F.X. Hu, J.L. Chen, Y.X. Li, Z. Wang, Z.Y. Gao, Y.F. Zheng, L.C. Zhao, G.H. Wu, W.S. Zan. IEEE Trans. Magn. 37, 4, 2715 (2001).

[4] E. Pagounis, R. Chulist, M. J. Szczerba, M. Laufenberg. Appl. Phys. Lett. 105, 5, 052405 (2014).

[5] V. Buchelnikov, I. Dikshtein, R. Grechishkin, T. Khudoverdyan, V. Koledov, Y. Kuzavko, I. Nazarkin, V. Shavrov, T. Takagi. J. Magn. Magn. Mater. 272-276, 3, 2025 (2004).

[6] E. Barmina, A. Kosogor, V. Khovaylo, M. Gorshenkov, M. Lyange, D. Kuchin, E. Dilmieva, V. Koledov, V. Shavrov, S. Taskaev, R. Chatterjee, L.K. Varga. J. Alloys Compd. 696, 310 (2017).

[7] S. Pramanick, S. Giri, S. Majumdar, S. Chatterjee, V.V. Koledov, A. Mashirov, A.M. Aliev, A.B. Batdalov, B. Hernando, W.O. Rosa, L. González-Legarreta. J. Alloys Compd. 578, 157 (2013).

[8] V.D. Buchelnikov, V.V. Sokolovskiy. Phys. Met. Metallogr. 112, 7, 633 (2011).

[9] A.P. Kamantsev, V.V. Koledov, A.V. Mashirov, E.T. Dilmieva, V.G. Shavrov, J. Cwik, A.S. Los, V.I. Nizhankovskii, K. Rogacki, I.S. Tereshina, Yu.S. Koshkid'ko, M.V. Lyange, V.V. Khovaylo, P. Ari-Gur. J. Appl. Phys. 117, 16, 163903 (2015).

[10] A. Zhukova, V. Rodionova, M. Ilyn, A.M. Aliev, R. Varga, S. Michalik, A. Aronin, G. Abrosimova, A. Kiselev, M. Ipatov, V. Zhukova. J. Alloys Comp. 575, 73 (2013).

[11] A. Sozinov, A.A. Likhachev, N. Lanska, K. Ullakko. Appl. Phys. Lett. 80, 10, 1746 (2002).

[12] F. Albertini, L. Morellon, P.A. Algarabel, M.R. Ibarra, L. Pareti, Z. Arnold, G. Calestani. J. Appl. Phys. 89, 10, 5614 (2001).

[13] E. Galieva, V. Valitov, R. Lutfullin, S.V. Dmitriev, A. Akhunova, M. Mukhametrakhimov. Mater. Sci. Forum 838-839, 350 (2016).

[14] Р.И. Бабичева, С.В. Дмитриев, Ю.А. Баимова, В.Г. Пушин. Письма о материалах 5, 4, 359 (2015).

[15] Р.Р. Мулюков, А.А. Назаров, Р.М. Имаев. Изв. вузов. Физика 51, 5, 47 (2008).

[16] Н.И. Коуров, А.В. Королёв, В.Г. Пушин, Е.В. Марченкова. ФTT 54, 10, 1999 (2012).

[17] R. Chulist, A. Böhm, E. Rybacki, T. Lippmann, C.-G. Oertel, W. Skrotzki. Mater. Sci. Forum 702-703, 169 (2012).

[18] И.И. Мусабиров, И.З. Шарипов, Р.Р. Мулюков. Изв. вузов. Физика 58, 6, 5 (2015). 
[19] И.И. Мусабиров, И.М. Сафаров, И.З. Шарипов, Р.Р. Мулюков, А.В. Маширов, В.В. Коледов. Журн. радиоэлектроники 1, 11 (2015).

[20] S. Taskaev, V. Buchelnikov, M. Ulyanov, D. Bataev, A. Fazlitdinova, K. Skokov, D. Karpenkov, V. Khovaylo, D. Zherebtsov, A. Pellenen. Solid State Phenom. 233-234, 238 (2015).

[21] R. Chulist, M. Pötschke, A. Boehm, H.-G. Brokmeier, U. Garbe, T. Lippmann, C.-G. Oertel, W. Skrotzki. MRS Proc. 1050, BB09-03 (2007).

[22] H. Morawiec, T. Goryczka, A. Drdzen, J. Lelatko, K. Prusik. Solid State Phenom. 154, 133 (2009).

[23] R. Chulist, W. Skrotzki, C.-G. Oertel, A. Böhm, H.-G. Brokmeier, T. Lippmann. Int. J. Mater. Res. 103, 5, 575 (2012).

[24] И.И. Мусабиров. Фундаментальные проблемы современного материаловедения 11, 2, 251 (2014).

[25] I.I. Musabirov, R.R. Mulyukov, V.V. Koledov. IOP Conf. Ser.: Mater. Sci.: Eng. 82, 012064 (2015).

[26] D.R. Nugmanov, O.S. Sitdikov, M.V. Markushev. IOP Conf. Ser:: Mater. Sci.: Eng. 82, 012099 (2015).

[27] О.Р. Валиахметов, Р.М. Галеев, Г.Ф. Хасанова. Перспективные материалы 12, 77 (2011).

[28] V.M. Imayev, R.A. Gaisin, E.R. Gaisina, R.M. Imayev, H.-J. Fecht, F. Pyczak. Mater. Sci. Eng. A 609, 34 (2014).

[29] R. Fayzullin, V. Buchelnikov, S. Taskaev, M. Drobosyuk, V. Khovaylo. Mater. Sci. Forum 738-739, 456 (2013).

[30] V.V. Sokolovskiy, R.R. Fayzullin, V.D. Buchelnikov, M.O. Drobosyuk, V.V. Khovaylo. J. Magn. Magn. Mater. 343, 6 (2013).

[31] A.A. Cherechukin, I.E. Dikshtein, D.I. Ermakov, A.V. Glebov, V.V. Koledov, D.A. Kosolapov, V.G. Shavrov, A.A. Tulaikova, E.P. Krasnoperov, T. Takagi. Phys. Lett. A 291, 175 (2001).

[32] D.L. Schlagel, Y.L. Wu, W. Zhang, T.A. Lograsso. J. Alloys Compd. 312, 77 (2000).

[33] R.W. Overholser, M. Wutting, D.A. Neumann. Scripta Mater. 40, 10, 1095 (1999).

[34] V.V. Khovailo, T. Takagi, A.N. Vasilev, H. Miki, M. Matsumoto, R. Kainuma. Phys. Status Solidi A 183, 2, R1 (2001).

[35] M. Kok, G. Pirge, Y. Aydogdu. Appl. Surf. Sci. 268, 136 (2013).

[36] И.И. Мусабиров, И.М. Сафаров, М.И. Нагимов, И.З. Шарипов, В.В. Коледов, А.В. Маширов, А.И. Рудской, Р.Р. Мулюков. ФТТ 58, 8, 1552 (2016). 